PontIFícIA UNIVERSIDADE CATÓLICA DO RIO DE JANEIRO

\author{
A importância da plataforma de \\ experiências de marca na Coca-Cola Brasil
}

Isadora Mizutani d'Avila

Trabalho de Conclusão de Curso

Centro de clências socials - CCS

DEPARTAMENTO DE AdMINISTRAÇÃO

Graduação em Administração de Empresas 
Isadora Mizutani d'Avila

\section{A importância da plataforma de experiências de marca na Coca-Cola Brasil}

Trabalho de Conclusão de Curso, apresentado ao programa de graduação em Administração da PUC-Rio como requisito parcial para a obtenção do título de graduação em Administração.

Orientador: Luis Fernando Hor-Meyll 


\section{Agradecimentos}

Agradeço aos entrevistados e amigos da Coca-Cola Brasil, que se disponibilizaram tão prontamente a ajudar no trabalho, e à minha família que me possibilitou finais de semana de isolamento para focar em escrever a monografia. À Alessandra pela confiança e apoio e a tantos outros professores do curso que inspiraram grande parte da minha motivação para realizar o trabalho. 


\section{Resumo}

d'Avila, Isadora. A importância da plataforma de experiências de marca na Coca-Cola Brasil. Rio de Janeiro, 2016. Número de páginas p. 34. Trabalho de Conclusão de Curso - Departamento de Administração. Pontifícia Universidade Católica do Rio de Janeiro.

O presente estudo tem como objetivo investigar a importância da plataforma de eventos e experiências para a Coca-Cola Brasil, usando como referência as ativações patrocinadas pela marca durante os Jogos Olímpicos Rio 2016 - o Parada Coca-Cola no Boulervard Olímpico e a promoção para os carregadores no Revezamento da Tocha Olímpica. A pesquisa foi realizada através de consultas a documentos internos da empresa e entrevistas com gerentes da companhia diretamente ligados aos projetos de brand experience. Como resultado, foram elaboradas recomendações com a finalidade de aprimorar o processo interno e contribuir na mensuração dos resultados adquiridos pelas experiências proporcionadas ao consumidor.

\section{Palavras- chave}

Experiência, eventos, marketing, marca, Coca-Cola

\section{Abstract}

d'Avila, Isadora. The importance of brand experience platform at Coca-Cola Brasil. Rio de Janeiro, 2016. Número de páginas p. 34. Trabalho de Conclusão de Curso - Departamento de Administração. Pontifícia Universidade Católica do Rio de Janeiro.

This study aimes to investigate the importance of the events and experiential marketing to Coca-Cola Brazil, using as reference sponsored activations during Rio 2016 Olympic Games such as Parada Coca-Cola at the Olympic Boulevard and promotions at the Olympic Torch Relay. The research involved interviews with company managers who are directly connected to brand experience projects. As a result, recommendations were generated in order to improve internal processes and contribute to the measurement of the results acquired through consumer's experiences.

Key-words

Experience, events, marketing, brand, Coca-Cola 


\section{Sumário}

1 Introdução 1

1.1 A empresa Coca-Cola 1

1.2 As experiências Coca-Cola e o valor da marca 3

$\begin{array}{lll}1.3 & \text { Objetivo da pesquisa } & 7\end{array}$

1.4 Oportunidade para a empresa $\quad 8$

2 Contextualização 9

2.1 História da Coca-Cola 9

$\begin{array}{lll}2.2 \text { Consumo de refrigerantes } & 10\end{array}$

$\begin{array}{ll}2.3 \text { Experiências para o consumidor } & 12\end{array}$

3 Pesquisa realizada $\quad 14$

3.1 Descrição do processo de pesquisa 14

3.2 Os entrevistados e suas atribuições 14

4 Análise das entrevistas 16

4.1 O retorno do investimento em marketing de experiência 16

4.2 Oportunidades encontradas 18

4.3 Envolvimento do consumidor com a marca 19

5 Recomendações e contribuições para a Coca-Cola Brasil 21

$\begin{array}{ll}\text { Referências } & 23\end{array}$

$\begin{array}{ll}\text { Anexo: Roteiro das Entrevistas } & 28\end{array}$ 


\section{Índice de Figuras}

Figura 1: Mapa de racionalização do consumo (Nielsen.a, 2016)...................... 2

Figura 2: Judoca Érika Miranda com a tocha Olímpica, na apresentação do uniforme dos condutores (Comitê Rio2016)......................................... 4

Figura 3: Simulação do stand dentro do Parque Olímpico (Diário do Rio, 2016) . 5 Figura 4: Foto da parte interna do stand dentro do Parque Olímpico (Fotógrafa amadora em blog, 2016)................................................................ 5

Figura 5: Simulação da vista externa do Armazém 3, no Boulevard Olímpico (A Cara do Rio, 2016) ......................................................................... 5

Figura 6: Show do Luan Santana, uma das atrações do Parada Coca-Cola (Agência Zapp News, 2016) ............................................................ 6

Figura 7: Consumo per capita de refrigerantes no Brasil 2010-2015 (ABIR, 2016) 


\section{Introdução}

\subsection{A empresa Coca-Cola}

O sistema Coca-Cola Brasil é o maior produtor de bebidas não-alcoólicas do país e possui uma linha de mais de 125 produtos em conjunto com a Leão Junior (Portal Coca-Cola Brasil, 2016). A operação é composta pela Coca-Cola Brasil e mais 10 empresas independentes, chamados fabricantes autorizados, que compram os concentrados de bebidas, produzem e distribuem o produto final aos pontos de venda.

A cia. Coca-Cola Brasil é responsável pela venda dos concentrados das bebidas e caracteriza-se por ser um negócio focado na área de marketing. Consequentemente, a marca Coca-Cola também é um ativo importante para a empresa, que há alguns anos enfrenta quedas de vendas devido à desaceleração do consumo de seu principal produto e, recentemente, pela crise que assola o Brasil.

A indústria de refrigerantes no país decresceu quase $6 \%$ no volume de produção de 2014 para 2015, segundo a Associação Brasileira das Indústrias de Refrigerante e de Bebidas Não-Alcoólicas (ABIR, 2016). De acordo com a consultoria Euromonitor, as sequenciais quedas no consumo e na produção de bebidas gaseificadas acompanha uma tendência mundial de preferência por produtos com menor teor calórico e menos açúcar, fazendo a movimentação para outras categorias como sucos naturais e água engarrafada (EUROMONITOR, 2016).

Além disso, o comércio varejista enfrenta o desafio apresentado pela situação econômica do brasileiro e sua relação com as ocasiões de compra e consumo. No último mês de março, a consultoria de estratégia empresarial Nielsen publicou em seu portal online o cenário de incertezas do consumidor no contexto em que o Brasil se encontra. Desemprego, endividamento e crise de confiança permearam o ano de 2015 e levaram o consumidor a encontrar alternativas para o consumo fora do lar, canais de compra, tamanhos de embalagem e até para marcas contidas nas cestas básicas - entre elas itens de limpeza e higiene, perecíveis, mercearia e bebidas não-alcoólicas (NIELSEN.a, 2016). Dessa forma, o brasileiro reduz seus gastos e busca maior custo 
benefício, racionalizando suas escolhas dentro e fora do ponto de venda, como se pode verificar na figura 1 .

\section{MAPA DE RACIONALIZAÇÃO DO CONSUMO}


Figura 1: Mapa de racionalização do consumo (Nielsen.a, 2016)

No mercado global, a The Coca-Cola Company anunciou ter recuado 4\% em seu faturamento no primeiro trimestre de 2016, quando comparado ao mesmo período do ano anterior (O ESTADO DE SÃO PAULO. Lucro da CocaCola cai no $1^{\circ}$ tri..., 2016). Entretanto, a marca da multinacional - esta que teve receita de 10,3 bilhões de dólares nos primeiros três meses deste ano - se mantém presente, sendo considerada Top do Top pela pesquisa Top of Mind (2015), realizada pelo Datafolha e divulgada na Folha de São Paulo em outubro de 2015. A pesquisa consiste em destacar as marcas das quais o consumidor tem maior facilidade de se recordar sem estímulo algum. A Coca-Cola está ao lado de outras gigantes, como Nike, Nestlé e Samsung na categoria Top do Top.

Além do Top of Mind de citações pelo Brasil, a empresa ocupa também o décimo lugar no ranking de marcas mais indicadas nas redes sociais. Pesquisa publicada em janeiro de 2016 e realizada pela SurveyMonkey em conjunto com a social@ogilvy, visava a entender como acontece o engajamento e a promoção espontânea de marcas nas redes sociais, como Facebook e Twitter, em 11 países - entre eles, o Brasil (DEARO, 2016). O primeiro lugar é ocupado pela Samsung e a Coca-Cola está logo após a Natura, única marca brasileira presente entre as 20 listadas. 


\subsection{As experiências Coca-Cola e o valor da marca}

Apesar de presente na memória do consumidor e relevante nas mídias sociais, a Coca-Cola não se contenta com os títulos. Para a empresa, "Não é apenas sobre a eficiência da publicidade. Trata-se de ajudar os consumidores a se juntarem e ficarem na franquia Coca-Cola, independentemente dos ingredientes que desejam controlar, incluindo seu consumo de açúcares adicionados, seja em bebidas ou quaisquer outras categorias que têm adição de açúcar", explica Ahmet Muhtar Kent, CEO da companhia, para a Marketing Week (RODERICK, 2016).

$\mathrm{Na}$ visão de Kent, o que fideliza o consumidor não são as campanhas de publicidade, mas o amor pela marca. "Sempre soubemos que o maior driver de consumo é a opinião própria. Na sequência temos a opinião de conhecidos, desconhecidos, canais de informação de nossa confiança e então, somente depois de tudo isso, estão os anúncios. Mas de onde vêm as nossas opiniões? Das nossas experiências" (MEDEIROS, 2016).

Keller (2001) expõe que o maior desafio para os profissionais de marketing hoje é fazer com que consumidores tenham o tipo certo de experiência com o produto ou serviço, de modo que seus desejos, pensamentos, sentimentos, crenças e percepções se conectem com a marca. Tal conexão, o brand love ${ }^{1}$, já é o objetivo final de todas as peças de marketing da Coca-Cola e o índice também está contemplado na mensuração dos resultados de cada comercial, promoção ou experiência - relatam fontes internas da organização.

Segundo Keller (2001), atingir amor de marca é derrubar alguns obstáculos e, de acordo com o modelo desenvolvido pelo autor, existem quatro perguntas que a empresa deve responder ao consumidor para que a marca adquira brand equity2: "Quem é você"; "o que é você"; "o que você tem" e "o que você e eu temos em comum". Seguindo esta ordem, a marca seria capaz de construir um relacionamento com seu consumidor ao sanar da quarta e última pergunta. $O$ autor ainda complementa que as experiências com a marca levam o consumidor a pensar e agir de forma a permitir que as empresas colham os frutos do brand equity, como frequência de consumo e recompra; lealdade com a marca; atitude positiva com os atributos do produto, gerando sentimento de pertencimento e prazer, e finalmente o nível mais alto de amor, que ocorre quando o consumidor se torna um embaixador da marca, engajando outros consumidores para além

${ }^{1}$ Brand Love: Refere-se ao amor declarado dos consumidores pela marca.

${ }^{2}$ Brand Equity: Valor da marca 
do consumo (exemplo: menções positivas nas redes sociais). Porém, o autor adverte que até mesmo as marcas mais fortes devem continuar investindo em atividades de construção de marca, para manter ou aumentar o valor da sua marca.

Foi esse o pensamento que levou a empresa a desenhar uma estratégia para a plataforma de eventos. Segundo o time de marketing estratégico das marcas Coca-Cola, Coca-Cola Zero e o último lançamento Coca-Cola com Stevia, algumas ações são possíveis quando se quer aproximar uma marca do consumidor e de seu dia-a-dia. Product Placement (entrada do produto na programação de novelas e seriados de televisão), patrocínio de eventos (como nas Olimpíadas) e redes sociais (Coca-Cola Taste Games: https://winnin.com/cocacolatastegames/) são exemplos de meios nos quais a companhia já vem atuando e não pretende parar para manter sua presença na cultura popular.

Experiências de marketing para o consumidor também representam uma estratégia importante. Durante o patrocínio das Olimpíadas Rio 2016, a CocaCola promoveu o revezamento da tocha por todo o país e fez duas grandes ativações, uma dentro do Parque Olímpico e outra no Armazém 3 da Zona Portuária - conhecida como Boulervad Olímpico -, o Parada Coca-Cola (mais informações: https://www.youtube.com/watch?v=xDefPUhe6nl). As experiências, que podem ser citadas como exemplos mais atuais da estratégia, traziam o consumidor para dentro do universo Coca-Cola, em uma imersão sensorial que unia o refrigerante com música, dança, esporte, o licenciamento Coca-Cola e muitos posts nas redes sociais.



Figura 2: Judoca Érika Miranda com a tocha Olímpica, na apresentação do uniforme dos condutores (Comitê Rio2016) 


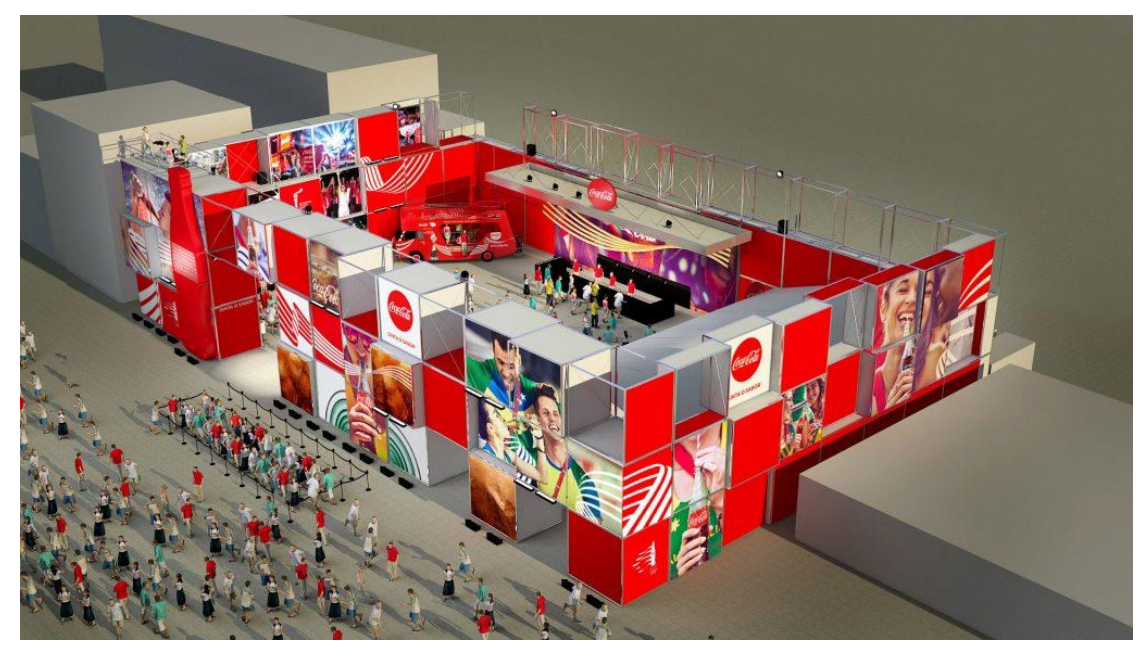

Figura 3: Simulação do stand dentro do Parque Olímpico (Diário do Rio, 2016)



Figura 4: Foto da parte interna do stand dentro do Parque Olímpico (Fotógrafa amadora em blog, 2016)

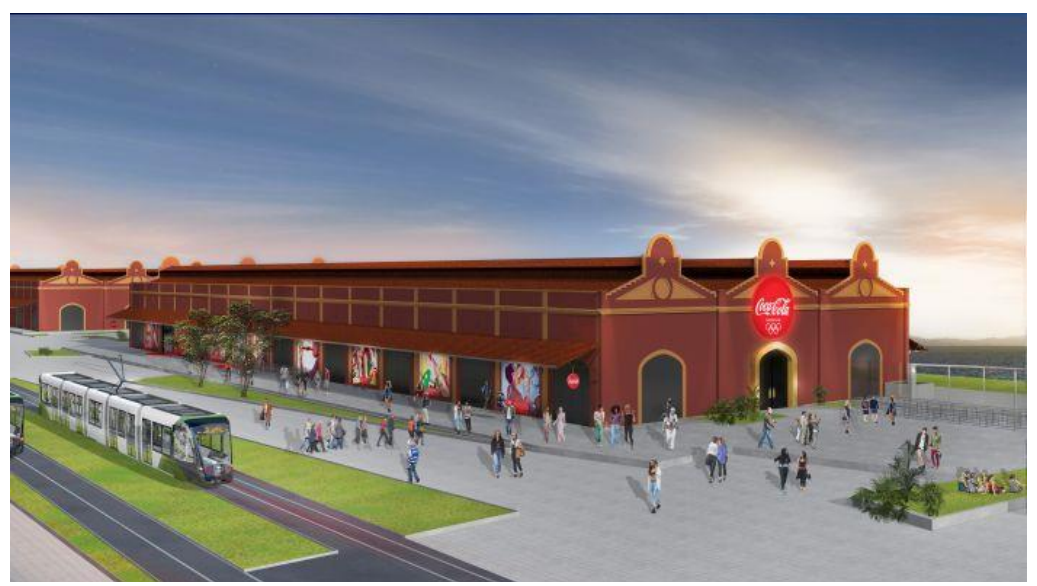

Figura 5: Simulação da vista externa do Armazém 3, no Boulevard Olímpico (A Cara do Rio, 2016) 




Figura 6: Show do Luan Santana, uma das atrações do Parada Coca-Cola (Agência Zapp News, 2016)

Em artigo publicado na Harvard Business Review, Pine II e Gilmore (1998) confirmam que os consumidores desejam ter experiências e que as empresas cada vez mais respondem a tal estímulo, atendendo ao público. Os autores ainda colocam que experiências estão no estágio mais elevado da diferenciação, fazendo delas uma oferta premium.

As ativações citadas cumpriam o que Pine II e Gilmore (1998) consideram a distinção entre a oferta econômica da experiência de marca: natureza memorável; atributos pessoais; suprimentos revelados durante o consumo; o comprador como convidado e as sensações como fator de demanda. $O$ refrigerante Coca-Cola era somente uma propriedade da marca, um bem industrial.

Solomon (2011) descreve que o envolvimento de uma pessoa com uma marca pode se dar com anúncios, com produtos ou no momento de decisão de compra. O envolvimento, explica o autor, é quando uma pessoa percebe o objeto com base nas suas necessidades, nos seus valores e seus interesses inerentes. Dessa forma, um consumidor pode se envolver menos ou mais com tal objeto, indo do que Solomon chama de inércia - estágio mais baixo - até a paixão.

A resposta que o consumidor dará sobre o tamanho de seu envolvimento é diretamente proporcional à participação deste com a mensagem, alerta o autor. Um anúncio na televisão torna o consumidor um espectador passivo, pois só está recebendo a mensagem. Já um panfleto físico, exige um pouco mais do consumidor, pois o processo de ler e refletir sobre a informação dá a ele uma 
participação mais ativa. Nesta linha, uma experiência de marketing estaria no topo do envolvimento do consumidor com o produto e com a mensagem, afinal, faz do consumidor uma parte essencial da ativação que, inclusive, pode ser diferente a partir das reações obtidas.

Entretanto, devido aos seus custos altíssimos, a brand experience ${ }^{3}$ ainda é discutida na empresa, já que não se sabe exatamente o retorno que pode ser conferido, afirma a gerente de marca do projeto Coca-Cola Vibezone em depoimento pessoal. Talvez economicamente os eventos não consigam se pagar, mas na memória do consumidor, a marca pode ser mais forte a cada experiência que proporciona. Porém, a empresa ainda não consegue ter essa confirmação.

Diante desde cenário, e levando em consideração que os projetos de patrocínio de eventos, ativação de marca em eventos e marketing de experiência representam um alto investimento para a empresa, este estudo pretende investigar a importância da plataforma de eventos para a marca Coca-Cola.

\subsection{Objetivo da pesquisa}

Este estudo pretende investigar as seguintes questões: (a) Experiências de marca trazem valor para a marca Coca-Cola? (b) Uma experiência pode trazer resultados mensuráveis para a companhia? (c) Como podem ser medidos esses resultados para serem replicados em outros projetos da empresa?

O estudo visa a entender se, uma vez memorável, a empresa pode esperar um resultado mensurável do evento. Dessa forma, a pesquisa será realizada através de consultas a documentos internos, publicações sobre o tema e entrevistas pessoais com gerentes que trabalham na empresa e se relacionaram com projetos de brand experience dentro do contexto do patrocínio da Olimpíada, como o Parada Coca-Cola e o revezamento da Tocha Olímpica.

As entrevistas em profundidade proporcionam uma oportunidade para investigar a experiência dos gerentes em relação às dificuldades de realizar uma experiência para o público, as barreiras encontradas dentro da organização e o retorno que se espera de um projeto que envolve brand experience. A pesquisa é de cunho exploratório, de forma a gerar insights e recomendações de inovações para a empresa dentro da economia da experiência.

${ }^{3}$ Brand Experience: Refere-se a experiências praticadas com verba e ativação de uma marca. 


\subsection{Oportunidade para a empresa}

O tema Marketing de Experiência é bastante recente, sendo pouco encontrado em estudos dentro da academia e ainda considerado informal para muitas empresas. A brand experience mostra-se, no cenário atual, uma importante ferramenta de conexão com o público-alvo, formando um canal direto entre uma marca e seus consumidores finais, como já citado.

Em tempos de redes sociais e tecnologia cada vez mais avançada, fidelizar consumidores (ou transformar um hater ${ }^{4}$ em neutro) também passa a ser crucial diante de tantas mensagens que chegam aos usuários principalmente no varejo, como é o caso da Coca-Cola. Entender os pontos de contato da composição do equity da marca, ou seja, o relacionamento desenvolvido torna-se estratégico para os departamentos de marketing, que têm seus projetos centrados no olhar para os compradores do produto.

Além disso, a indústria de entretenimento já é o terceiro maior mercado do mundo, mantendo-se com demanda mesmo em períodos de recessão econômica. Dados da PricewaterhouseCoopers (PwC) de 2014 indicam que o setor movimentou US\$42 bilhões no ano e projetam um faturamento de aproximadamente US\$69 bilhões em 2019. Ainda neste contexto, a indústria de shows e eventos tem destaque por ser a de maior rentabilidade (PWC, 2014).

No Brasil, a expectativa de crescimento é de $39 \%$ no consumo de shows até 2018, afirma Gardênia Rogatto, especialista em entretenimento da PwC nacional. O país já é o segundo maior mercado do ramo na América Latina, perdendo somente para o México, e a receita deste segmento apresentou incremento de $24 \%$ entre os anos de 2010 e 2014 (ENTERTAINMENT AND MEDIA OUTLOOK, 2015).

Para a Coca-Cola, o estudo é de extrema relevância, posto que propõe mais razões pelas quais a empresa deve enxergar as experiências de marketing e a absorção da economia da experiência como um investimento que gera retorno. Assim como aprimoramento de fórmulas e espaço nos supermercados, um evento, show, festival ou festa, podem proporcionar resultados palpáveis, representando uma forma de engajar o consumidor a ser embaixador da marca. Para tanto, a empresa ainda precisa entender a melhor forma de padronizar a mensuração de tais resultados em seus projetos com brand experience.

${ }^{4}$ Hater: Termo utilizado na internet para se referir a pessoas que criticam muito uma marca ou ícone, postando sempre menções negativas. 


\section{Contextualização}

\subsection{História da Coca-Cola}

O produto que hoje só não está presente em dois países do mundo - Cuba e Coréia do Norte -, foi criado em 1886 por um farmacêutico na cidade de Atlanta, o Doutor Pemberton. Segundo as crônicas, o farmacêutico desenvolveu um xarope que, misturado com água com gás, resultava no "delicioso e refrescante" refrigerante, slogan utilizado na época. Vendendo copinhos a cinco centavos, o negócio realmente só deslanchou após a morte de Pemberton e a administração de Asa G. Candler, fundador da The Coca-Cola Company. Em 1895, todo o território dos Estados Unidos já consumia Coca-Cola e, em 1916, surgia a garrafa inovadora de formato inconfundível, a Contour (PORTAL ONLINE COCA-COLA BRASIL).

A rede global do refrigerante começou a se desenhar nos anos 1920, mas somente durante a Segunda Guerra Mundial que o mundo pôde experimentar o sabor de Coca-Cola, tornando-a um símbolo de amizade (PORTAL ONLINE COCA-COLA BRASIL). Na década de 70, um dos vídeos mais icônicos para a companhia até os dias de hoje surgiu: jovens se reuniram no topo de uma colina na Itália para cantar "eu gostaria de comprar uma Coca-Cola para o mundo" ("I'd like to buy the world a Coke", em inglês. Disponível em: https://www.youtube.com/watch?v=1VM2eLhvsSM).

Embora o Brasil seja o quarto maior mercado do mundo, a organização vem sofrendo altos e baixos nos últimos cinco anos. Mesmo assim, a marca detém cerca de $80 \%$ do share de mercado dentro do segmento de refrigerantes de cola no Brasil e sua versão regular representou mais de $40 \%$ do volume de refrigerantes vendidos no país em 2015 (NIELSEN.b, 2016).

Se antes o desafio era fazer com que o mundo bebesse Coca-Cola para se tornar um lugar mais feliz, hoje é o oposto: os gerentes de marca da empresa vêm destacando a necessidade de converter o amor que as pessoas sentem pela marca em consumo dos produtos do portfólio. Em documentos internos da organização que descrevem os objetivos para os próximos quatro anos, a empresa mostra para onde está caminhando quando declara que a saúde da 
marca está boa, o que falta é fortalecer o caminho entre a admiração do consumidor e a compra do produto.

Por isso, constatam que, entre outras ações, a "experiência de beber uma Coca-Cola gelada" ainda é uma forte candidata a relembrar o valor do refrigerante e retomar o consumo como forma de lazer, incluindo opções de embalagens menores e versões com redução de açúcar. Além disso, o pensamento de inovação traz celebração e entretenimento como um pilar fundamental dentro do planejamento até 2020.

A estratégia atual da marca é de fazer parte do contexto dos eventos para se tornar a protagonista. A plataforma de eventos hoje volta a unir marca e produto, amor e consumo, prometendo experiências ainda mais refrescantes.

\subsection{Consumo de refrigerantes}

A maior parte dessas experiências acontece no eixo Rio de Janeiro-São Paulo, cidades com grande concentração de jovens entre 12 e 18 anos. $O$ Sudeste do Brasil abriga quase $40 \%$ dos adolescentes nesta faixa etária, segundo o Censo de 2010, do Instituto Brasileiro de Geografia e Estatística (IBGE, 2010). Além disso, documento elaborado pelo Departamento de Pesquisa e Estudos Econômicos do Bradesco sobre a indústria de bebidas no Brasil apresenta: "O estado de São Paulo e o Grande Rio de Janeiro respondem por cerca de $40 \%$ do consumo de refrigerantes no país", de acordo ainda com dados de 2010 (DEPEC Bradesco, 2016).

No entanto, o consumo per capita da categoria vem decrescendo, conforme mostram resultados divulgados pela Associação Brasileira das Indústrias de Refrigerantes e Bebidas Não-Alcoólicas (ABIR, 2016). Em 2014, estima-se que a boa performance esteja diretamente ligada à Copa do Mundo de Futebol, que teve o Brasil como anfitrião, e a um longo verão, explica Gloria Tittoto (NIELSEN.c, 2016).

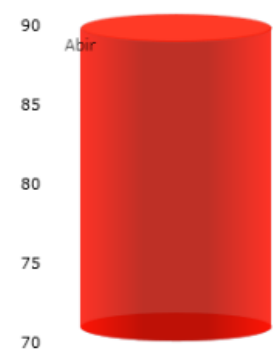

2010



2011

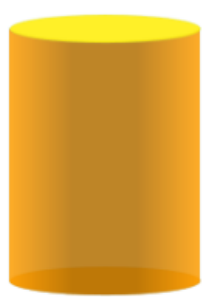

2012



2013



2014

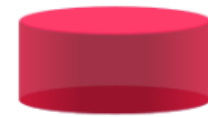

2015

Figura 7: Consumo per capita de refrigerantes no Brasil 2010-2015 (ABIR, 2016) 
Mas a queda do consumo de determinadas categorias de alimentos não atinge os resultados do comércio de supermercados, constatam dados da Associação Brasileira de Supermercados (ABRAS, 2016). Segundo o Índice Nacional de Vendas - pesquisa mensal realizada pela Associação e com um universo de $60 \%$ das lojas do setor -, desde 2001 as variações nominais são positivas quando comparadas ao ano anterior, caracterizando uma estabilidade na média de vendas dos supermercados do Brasil até o ano passado.

Assim, pode-se inferir que a específica queda no consumo de refrigerantes está atrelada à recente mudança nos hábitos de pessoas no mundo inteiro. Como já citado, o consumidor brasileiro tem ainda mais razões para alterar sua forma de comprar, comer e escolher marcas: a crise. De acordo com analistas da Nielsen para o portal Paraíba Total (2016), há cinco características que o varejo deve ficar atento para ser empático ao seu comprador:

1. O consumidor está mais atento ao preço

2. Troca conveniência por economia

3. Está disposto a trocar de marca

4. É conectado e não abre mão do que gosta

5. Já considera o canal online como de compras

Além de estar mais consciente de seus gastos, o consumidor está mais consciente dos ingredientes que ingere também. Na média do primeiro semestre de 2016, aproximadamente $60 \%$ da população brasileira declarou ter a percepção de que Coca-Cola é um refrigerante prejudicial à saúde, informam dados da pesquisa Brand Guidance System sobre consumo declarado para a Coca-Cola Brasil (MILLWARD BROWN, 2016).

Sobre o tema, a empresa responde em sua página Coca-Cola Journey: "Todos os alimentos e bebidas podem se ajustar a uma dieta balanceada, adequada do ponto de vista nutricional e apropriada em termos calóricos. Para tanto, devem ser consumidos com moderação, com tamanho apropriado das porções e combinados com atividade física regular. A maioria dos especialistas e instituições de nutrição, como a Academy of Nutrition and Dietetic, concorda que o mais importante para a manutenção da saúde é o padrão geral dos alimentos na dieta total e não a ingestão de um único alimento ou refeição" (COCA-COLA JOURNEY, 2016). 


\subsection{Experiências para o consumidor}

Carù e Cova (2003) revisitaram os conceitos de experiências de consumo e experiência para o consumidor em artigo para a Marketing Theory Articles e concluíram suas finalidades bem distintas. Segundo os autores, enquanto a experiência de consumo segue o processo de estágios de compra e pretende causar uma transformação no momento do consumo, ativando a memória do consumidor com momentos do passado ou uma afinidade; a experiência para o consumidor espera ser memorável e inesquecível, engajando-o através de uma interação que fique marcada nele e quebre a monotonia do dia-a-dia.

Dentro do conceito de experiências para o consumidor, está o Marketing Experiencial (ou Experimental) que, ainda sob o artigo de Carù e Cova (2003), se encaixa no quadrante de experiência para o consumidor com definição de extraordinário. O marketing experiencial, afirma Schmitt (1999), caminha para uma tendência de integração das experiências individuais dentro de uma visão holística, na qual os produtos não são mais pacotes de benefícios funcionais, mas alavancas que proporcionam experiências para o consumidor.

Em seu artigo Experiential Marketing, Schmitt (1999) defende que os meios tradicionais de marketing - tais como rádio, televisão e jornal - se desenvolveram durante a era industrial, quando consumidores eram racionais e os métodos bastante quantitativos e analíticos. Hoje, explica o autor, vivemos a revolução das comunicações; a inacabável oferta de informação e a era do branding (marcas). Neste contexto, a experiência do consumidor vira o foco das atenções, já que proporciona valores sensoriais, emocionais e comportamentais que substituem aqueles benefícios funcionais atribuídos aos produtos.

O valor da marca, então, é definido por Aaker (1991) como um ativo que está ligado à marca, ao nome e ao símbolo que possui. No livro Brands and Branding (2003), de Rita Clifton e John Simmons, é citada uma pesquisa realizada pelo Carlson Marketing Group, na qual tentava-se quantificar a qualidade do relacionamento entre consumidores e uma marca. A pesquisa com 16.000 consumidores britânicos trouxe à tona uma ligação direta entre a intensidade da relação com a marca e os lucros da empresa. Com o estudo, concluiu-se que os gastos, a retenção e a potencial recomendação de uma marca para outros por parte do consumidor são significativamente influenciados pela intensidade de tal relacionamento (SMITH, 2003). Para os pesquisadores do Carlson Marketing Group, uma relação forte é constituída por confiança (os consumidores entendem que a marca irá cumprir suas promessas e respeitá- 
los); comprometimento (quando o consumidor sente que tem um afeto emocional e de longo prazo com a marca) e mutualidade (reciprocidade da afinidade, ou seja, mútuos respeito, valores compartilhados e alinhamento de expectativas) (SMITH, 2003).

Dessa forma, é possível perceber como o emocional causa cada vez mais impacto nas decisões do consumidor. Holbrook e Hirschman (2014) alertam que o consumo já começou a ser visto como um momento de sentir, se divertir e de viver fantasias - o que eles denominam "a visão experiencial". Os autores explicam que a busca por entretenimento, lazer e artes vem crescendo e que isso pode ser considerado um sinal para a importância do desejo de vivenciar dos consumidores. Além disso, se as emoções já estão tão presentes nas ocasiões de consumo, esse pode ser um caminho de sucesso da perspectiva de experiências - onde a decisão de compra se torna uma pequena etapa dentro de todos os fatores que compõem uma experiência para o consumidor (HOLBROOK e HIRSCHMAN, 2014). 


\section{Pesquisa realizada}

\subsection{Descrição do processo de pesquisa}

Para responder às questões levantadas neste estudo foram realizadas entrevistas com gerentes da empresa que trabalham com projetos relacionados à brand experience. As entrevistas foram realizadas entre o dia 23 de setembro até o dia 4 de outubro de 2016, com quatro gerentes da Coca-Cola Brasil. Os entrevistados participaram de uma conversa individual, seguindo um roteiro semiestruturado, com o qual poderiam se sentir livres para adicionar informações que julgassem relevantes e também deixar de responder às perguntas que não fizessem parte da sua área de atuação.

O roteiro semiestruturado, segundo Manzini (1990), tem a vantagem de permitir que novas questões surjam no momento da entrevista, colaborando para o intuito qualitativo do estudo, de coletar informações subjetivas e não científicas. As perguntas contidas no roteiro visavam a destacar as opiniões dos entrevistados e conectar a idealização aos resultados das experiências usadas como exemplos. O roteiro completo pode ser encontrado no anexo I do estudo.

Os entrevistados foram abordados dentro da organização e tinham como função a aprovação ou execução de partes que compunham as experiências Revezamento da Tocha Olímpica e Parada Coca-Cola. A escolha deles ocorreu por meio de indicações dentro do time do projeto de Olimpíadas e todos tinham conhecimento da finalidade exploratória e acadêmica da entrevista.

\subsection{Os entrevistados e suas atribuições}

Os entrevistados têm entre seis meses e quatro anos de empresa e todos fizeram parte do projeto Olimpíadas dentro da Coca-Cola. No entanto, cada um tem um diferente histórico antes do time de projeto e possuem bagagens distintas em seu relacionamento com experiências ao consumidor.

A entrevistada 1 trabalha da Coca-Cola Brasil há quatro anos e, antes, passou pela área de Pesquisa (Knowledges and Insights). Sua função com as experiências era de aprovadora de todos os materiais que fossem impactar o consumidor de alguma forma, fossem físicos ou digitais. Além disso, durante a 
execução do evento, era de sua responsabilidade a proteção das marcas - ou seja, gerenciamento de filas, venda de produtos concorrentes no arredores e etc.

O entrevistado 2 acompanhou o revezamento da tocha e, mais especificamente, os condutores que participaram da promoção para serem carregadores pela Coca-Cola. Antes do projeto, fazia parte do departamento de Marketing, atuando no time de Promoções. Sua performance era bastante próxima ao consumidor e perdurou os 13 meses entre o início da promoção "Carregar a Tocha Olímpica Coca-Cola \#issoéouro" (detalhes da mecânica no Blog Coca-Cola.Design.News: http://cocacoladesignnews.blogspot.com.br/2015/08/promocao-carregar-tocha-olimpicacoca-cola-issoeouro.html) até o final do revezamento, quando a Pira Olímpica foi acesa.

O entrevistado 3 é advogado de formação e atuou também no projeto de Copa do Mundo pela Coca-Cola no Brasil. Sua atuação na Olimpíada foi juntamente aos comitês - Comitê Olímpico Brasileiro (COI) e Comitê organizador local Rio 2016 - gerenciando o uso das marcas dentro do contexto do patrocínio realizado.

A entrevistada 4, por fim, faz parte hoje do time de Brand Experience, dentro do Marketing, e há cinco anos trabalha com experiências de marca para o consumidor. No Parada Coca-Cola, atuava na elaboração e execução da programação do palco do evento, ou seja, gerenciando o contato com influenciadores e artistas que se apresentariam ali. 


\section{Análise das entrevistas}

A seguir, serão apresentadas as respostas dadas pelos entrevistados em relação às estratégias de marketing de experiências da Coca-Cola Brasil. Em seguida, destacam-se algumas oportunidades para a empresa de acordo com a pesquisa realizada e a opinião dos entrevistados sobre o envolvimento do público com a marca, quando fazem parte de uma brand experience.

\subsection{O retorno do investimento em marketing de experiência}

A empresa reconhece a importância do mercado de eventos e o valor que o consumidor atribui à vivência e à experimentação. Durante as entrevistas realizadas, os gerentes destacaram a importância de manter experiências nos projetos para a empresa e para o público-alvo:

"Eu não vejo ninguém aqui abrindo mão de ter uma área de 'assets and partnerships', eventos, experiência... Independente do volume não estar entregando da forma como se espera, independente da economia não estar boa,

ninguém vai abrir mão. Pode reduzir e fazer opções, mas continuo vendo experiência de marca como uma prioridade da companhia." (Entrevistado 3)

"A gente, como consumidor, dá muito valor para o que está sentindo, para aquela experiência, e muito menos para o que estamos vendo na TV. Porque você recebe tanta comunicação, tanto banner, que às vezes você nem vê o que está acontecendo. Se a gente (Coca-Cola) não consegue falar bem direto, você se perde. (...) Então o consumidor valoriza muito e ele acaba comprando a ideia daquela marca de uma maneira muito mais fácil do que se ele ficasse só sendo impactado o tempo inteiro." (Entrevistada 4)

Assim, apesar de reconhecer que não pode deixar de investir em experiências como ferramenta de comunicação com o consumidor, os entrevistados entendem que o alcance de uma experiência não é massivo e impacta muito menos pessoas do que os meios tradicionais de marketing. 
"Você participar de uma brand experience é o topo da pirâmide de engajamento, então é um universo super reduzido comparado a um universo de pessoas que compram a marca." (Entrevistado 2)

“(...) você não tem como fazer uma experiência para 10 milhões de pessoas, salvo quando você patrocina um grande evento, por exemplo."

(Entrevistado 3)

"E a experiência cria isso, você consegue passar muito mais valor do que aquilo é, você acaba engajando e conquistando esses consumidores de uma forma mais nichada - porque não dá pra fazer uma experiência para 290 milhões de pessoas ou 100 milhões como é um anúncio no Big Brother (Brasil)."

(Entrevistada 4)

Além disso, após a execução de uma experiência, como a Parada CocaCola e o revezamento da tocha, a empresa também precisou tomar decisões para avaliar seu sucesso. Definir métricas e metas para o desempenho de uma experiência com o consumidor não é uma tarefa fácil, segundo os gerentes. Por isso, cada projeto acaba tendo uma fotografia de sucesso diferente, tornando a comparação ainda mais difícil.

“(...) porque em brand experience você realmente não tem uma métrica específica, pelo menos dentro da companhia. Você não fala de número de pessoas ou algo específico. Não vai mexer no brand love de uma maneira imediata, todo mundo que já trabalhou com Pesquisa aqui sabe que vai demorar para ter algum retorno." (Entrevistada 1)

"A gente está falando da Parada Coca-Cola, que era um projeto de jogos olímpicos, no meio do boulevard olímpico, focado em adolescente, o retorno esperado era engajar o adolescente." (Entrevistada 1)

"falando sobre o revezamento da tocha) o objetivo era ser a marca mais associada ao evento, ser um 'warm up' pros jogos. (...) Todas as pesquisas que a gente teve até agora, mostraram que Coca-Cola foi a marca mais associada ao evento, o que é legal." (Entrevistado 2) 
"O que a gente espera muito desse retorno, quando a gente faz essas experiências aqui, é o 'earned', é o quanto você ganha das pessoas divulgando aquilo. E é uma coisa muito natural, porque você espera que as pessoas gostem tanto que elas queiram contar." (Entrevistada 4)

Como citado na fala da entrevistada 1, a empresa espera que, no longo prazo, possa ter também um retorno de amor de marca. Carroll e Ahuvia (2006) em artigo para a Marketing Letters definem o brand love como "o degrau de apego emocional que um consumidor satisfeito tem por uma marca em particular", ou seja, um consumidor apaixonado por uma marca, além do apego por esta, pode agir de forma a avaliá-la positivamente, ter emoções positivas em resposta a esta e até mesmo fazer declarações de amor a esta, defendem os autores.

Mas este degrau está no topo da pirâmide do relacionamento entre o consumidor e a marca e, com isso, existem obstáculos que devem ser ultrapassados. Neste caminho entre desenvolver experiências para 0 consumidor, derrubando barreiras internas, e mensurar a performance após o término da experiência, os entrevistados enxergam algumas oportunidades que serão descritas a seguir.

\subsection{Oportunidades encontradas}

A primeira dificuldade mencionada foi a quantidade de alinhamentos e burocracia dentro da organização. Por mais interessante que seja a experiência em sua concepção, é preciso escalar para tantos níveis de decisão, que muitas vezes a iniciativa perde a força.

"Aqui dentro, de tudo que eu acompanhei do início do projeto, de como foi desenvolvido, a barreira foi conseguir passar todos os níveis de decisão, estar todo mundo alinhado com todos os pontos." (Entrevistada 1)

A segunda dificuldade mencionada fala de produtividade. $O$ entrevistado levantou uma forma da companhia executar novos eventos em um menor espaço de tempo e com menor investimento, aperfeiçoando o processo e se relacionando com o público-alvo. 
"Existem discussões internas de que eventos proprietários, criados por nós, protagonizados por nós, dão retorno dentro do nosso público-alvo de forma mais efetiva, num prazo menor e com um custo infinitamente menor do que um grande patrocínio que você tem que dividir com pelo menos outras 40 marcas."

(Entrevistado 3)

Por fim, uma oportunidade que a empresa precisa estar atenta é a de desenvolver uma padronização de tempo e método em sua avaliação pósexperiência. Com a dificuldade de mensuração e estabelecimento de métricas diferentes por evento, todo o histórico de aprendizados e pontos fortes pode ficar perdido, já que monitorar os acontecimentos se torna complicado.

"Eu acho que experiência você vai sabendo os resultados dela com o tempo, não é só ali no momento. Então, a gente fez essa experiência incrível da Parada Coca-Cola, o earned foi incrível, todo mundo postou. (...) Mas se daqui a três anos essas pessoas que viram isso nem lembrarem, eu não sei se foi tão impactante como a gente achou no momento. (...)Tem que fazer pesquisa, esperar mais tempo, ir mais a fundo nessas pessoas, não é só cravar uma métrica exata." (Entrevistada 4)

\subsection{Envolvimento do consumidor com a marca}

Quando perguntados sobre o quanto acreditavam que os consumidores dos dias de hoje valorizam vivenciar uma experiência de marca, os entrevistados não discordaram: experiências são fundamentais para a manutenção do valor da marca. Indo além, pediu-se para que eles dessem uma nota, em uma escala de 0 a 10, metrificando o tamanho do envolvimento que o marketing experimental causa entre o público e a marca em questão.

"Vou dar aqui um 9, porque uma brand experience sempre aproxima 0 consumidor da marca. O que vai fazer uma aproximação boa ou ruim vai ser o tipo de experiência que a pessoa vai ter." (Entrevistada 1)

"Eu acho que 10. Cada vez mais as marcas precisam sair do core business que elas fazem. Então, assim, a Coca-Cola é uma empresa de bebidas, é claro que vender bebida continua sendo o principal objetivo da companhia, mas eu acho que as marcas estão se desafiando, tem que se desafiar mesmo, a 
fazerem novas coisas, a extrapolarem um pouco os limites do que elas fazem."

(Entrevistado 2)

"Se você conseguir atingir o melhor ponto, o ponto de maior equilíbrio entre todos esses interesses, eu acho que uma experiência de marca pro consumidor, no envolvimento dele com a marca... eu atribuiria uma nota 8." (Entrevistado 3)

“É 10, completamente 10. (...) Por mais que a pessoa talvez nem goste do seu produto, mas ela viveu uma experiência em algum lugar tão bacana, que às vezes ela não precisou nem provar, mas aí você não tem uma pessoa que vá consumir, mas você também não tem um 'hater', que vai ficar tipo destruindo sua marca. (...) O que é importante também, você tem que tentar mostrar para as pessoas que te atacam um pouco mais de como você é." (Entrevistada 4)

Dessa forma, pode-se perceber que os entrevistados reconhecem o valor do investimento em brand experience, visto que criam um maior vínculo com consumidores e não consumidores dos produtos de seu portfólio. Como destacado pelos gerentes, além de trazer uma solução para uma necessidade latente do público-alvo, as experiências ainda cativam quem não aprecia o produto para que essa pessoa não se torne alguém que odeia e difama a marca.

No entanto, a dificuldade apresentada pela companhia é no que tange à mensuração dos resultados após a realização do evento ou promoção junto aos consumidores. Por se tratar de métricas subjetivas, muitas vezes mudam de projeto para projeto, o que não é o ideal se a empresa deseja consolidar sua plataforma de experiências e eventos.

Por isso, a seguir serão introduzidas algumas recomendações de possíveis maneiras que a Coca-Cola pode trabalhar para descobrir como colher os frutos de uma ação de marketing experiencial. Fugindo de metas científicas e específicas, a empresa tem um caminho inicial de exploração para, então, conseguir definir a melhor forma de projetar e medir os retornos. 


\section{Recomendações e contribuições para a Coca-Cola Brasil}

Após entender o contexto da indústria, analisar os dados do mercado consumidor e conversar com os gerentes, apresenta-se recomendações a fim de aprimorar e desenvolver a plataforma de eventos e experiências de marketing já existente na Coca-Cola. Buscando o suporte das bibliografias disponíveis e percebendo a dificuldade que a empresa passa para acompanhar os resultados de uma ação com tamanho investimento envolvido, as orientações aqui sugeridas servem como contribuição para a multinacional. A primeira recomendação para a multinacional é redefinir seu processo de alinhamento dos projetos, uma vez que a quantidade de degraus de decisão é grande e acaba atrasando a operação. A demora na aprovação dos itens que compõem a experiência pode fazer até com que a empresa perca oportunidades do contexto ou de modismos que são interessantes para entreter o público-alvo adolescente.

Neste momento, faz-se necessário entender as teorias da economia da experiência e sua relação com amor de marca e envolvimento do consumidor. Então, a Coca-Cola poderia iniciar um trabalho exploratório junto a consumidores que vivenciaram alguma de suas experiências visando a entender o que percebeu de positivo e negativo, construindo um histórico de aprendizados que pode ser útil nos próximos projetos e que ainda não é realizado pela empresa.

Além da pesquisa com o público que passou pela experiência, os entrevistados citaram a importância do meio digital e das interações em tempo real, como postagens nas redes sociais e menções positivas sobre o momento vivido. Esse resultado em forma de "ganho" (earned) já é uma métrica utilizada e foi bastante consultada durante os dias do Parada Coca-Cola, que contava com um time especial para analisar o volume diário de citações do público. Da mesma forma, para o revezamento da tocha, os entrevistados ressaltaram que a fotografia de sucesso da promoção como um todo era fazer da Coca-Cola a marca mais citada durante o período de aquecimento para a Olimpíada de 2016 e que os resultados estavam sendo medidos por meio de pesquisas desenvolvidas para a companhia.

Por fim, outro fator discutido internamente, segundo os relatos, é a produtividade. A inteligência de se fazer mais com menos - ou em menos tempo 
- também é importante para uma organização com as dimensões da Coca-Cola. Entender quais foram os retornos em comparação com o investimento alocado ou em quanto tempo a empresa colhe os frutos em relação ao valor dispendido na atividade, são indicadores que podem pesar no momento de apresentar argumentos na avaliação do projeto.

Sendo assim, as recomendações são uma combinação de três esforços:

1. Aprendizado: Buscar entender os sentimentos de participantes de experiências para construir um histórico;

2. Earned: Menções espontâneas em redes sociais e mídia online, em conjunto com o time de real time marketing da empresa, podendo variar a meta;

3. Produtividade: de quanto foi ou em quanto tempo foi o retorno em relação ao investimento em cada experiência.

Os impactos destas iniciativas para medição são positivos para a empresa, que poderá ter bases de comparação e melhores dados no momento de estudar a viabilidade de uma nova experiência ou de desenhar uma inovação no meio, como eventos proprietários e ações que fogem da venda de refrigerantes e bebidas. Com as soluções propostas, a Coca-Cola poderia ter uma visão mais qualitativa com as opiniões do seu público e também uma visão financeira, calculando de uma maneira um pouco diferente o retorno por investimento.

Sendo assim, a questão não é mais "fazer ou não fazer experiências para o consumidor?", pois, com o auxílio de diversas fontes, sabe-se que o caminho para fortalecer a marca e estimular a criação de vínculos com o consumidor está na aproximação do público-alvo. O que a organização precisa agora é de ações mais táticas, que aprofundem o "como fazer", ou seja, como medir, como estimular a inclusão de experiência nas campanhas, como garantir a verba necessária e, principalmente, como montar um time que olhe para a estratégia e queira inovar, ainda que isto implique em um custo de tempo para alinhamento interno. 


\section{Referências}

\section{Livros e Artigos:}

AAKER, D. Managing Brand Equity: Capitalizing on the value of a brand name. Nova lorque, 1991.

ARAUJO, F. O lançamento de uma nova embalagem do refrigerante Coca-Cola: Um estudo de caso sobre o lançamento da mini pet pela empresa Rio de Janeiro Refrescos. Revista Pensamento Contemporâneo em Administração, v. 9, n.2, p. 113-128, 2015.

CARROLL, B. A. e AHUVIA, A. C. Some antecedents and outcomes of brand love. Marketing Letters, 2006. Volume 17, p. 79-89.

CARÚ, A. e COVA, B. How to facilitate immersion in a consumption experience: Appropriation operations and service elements. Journal of Consumer Behaviour, Milão, fev. 2006. Volume 5, p. 4-14.

CARÚ, A. e COVA, B. Revisiting consumption experience: A more humble but complete view of the concept. Marketing Theory Articles, 2003. Volume 3, p. 267-286.

HOLBROOK, M. B. e HIRCHMAN, E. C. The experiential aspects of consumption: Consumer fantasies, feelings, and fun. Journal of Consumer Research, set. 1982. Volume 9, p. 132-139.

KELLER, K. L. Building Customer-Based Brand Equity: A blueprint for creating strong brands. Marketing Science Institute, n. 01-107, 2001.

MAZINI, J. E. Entrevista semi-estruturada: Análise de objetivos e de roteiros. Rio de Janeiro, 1990. 154 p. Dissertação de Pós Graduação em Educação - Departamento de Educação Especial: Universidade Estadual Paulista de Marília

PINE II, J. and GILMORE, J. H. Welcome to the Experience Economy. Harvard Business Review, Jul-Ago, 1998.

PLASCAK, N. Resenha: A marca pós-moderna: poder e fragilidade da marca na sociedade contemporânea. Revista Signos do Consumo, v. 1, n.1, p. 132-136, 2009.

SCHMITT, B. Experiential Marketing. Journal of Marketing Management, 1999. Volume 15, p. 53-67.

SMITH, S. Brands and Branding. Londres: Profile Books Ltd, 2003, p. 97-111.

SOLOMON, M. R. O Comportamento do Consumidor. 9ª edição. Porto Alegre. Editora Bookman. 2011. Páginas 163-171. 


\section{Sites:}

ABIR (Associação Brasileira das Indústrias de Refrigerantes e Bebidas NãoAlcoólicas). Refrigerantes. Disponível em: <http://abir.org.br/osetor/dados/refrigerantes/>. Acesso em: 09 de setembro de 2016

ABRAS (Associação Brasileira de Supermercados). Índice de Vendas. Disponível em: <http://www.abras.com.br/economia-e-pesquisa/indice-devendas/>. Acesso em: 09 de setembro de 2016

Agência Zapp News. Luan Santana se apresenta em lounge no Boulevard Olímpico. Rio de Janeiro, 13 ago. 2016. Disponível em: $<$ http://aibnews.com.br/colunas/luan-santana-se-apresenta-em-lounge-noboulevard-olimpico.html>. Acesso em: 14 de outubro de 2016.

Associação Brasileira de Empresas de Eventos. Mercado de eventos oferece vagas para vários tipos de profissional. Rio de Janeiro, 2015. Disponível em: $<$ http://www.abeoc.org.br/2015/03/mercado-de-eventos-oferece-vagas-paravarios-tipos-de-profissional/>. Acesso em: 01 de junho de 2016.

BEATTIE, A. One down, two to go: Coca-Cola returns to Myanmar after 60 years. AdvertisingAge, 11 set. 2012. Disponível em: <http://adage.com/article/global-news/coca-cola-returns-myanmar-60years/237123/>. Acesso em: 08 de setembro de 2016.

Blog Coca-Cola.Design.News. Carregar a Tocha Olímpica Coca-Cola \#issoéouro. Disponível em: <http://cocacoladesignnews.blogspot.com.br/2015/08/promocao-carregar-tocha-olimpicacoca-cola-issoeouro.html>. Acesso em: 09 de setembro de 2016.

BOUÇAS, C. Coca-Cola fecha trimestre com lucro acima de US\$1 bi e receita menor. Valor Econômico, 09 fev. 2016. Disponível em: <http://www.valor.com.br/empresas/4428532/coca-cola-fecha-trimestre-comlucro-acima-de-us-1-bi-e-receita-menor>. Acesso em: 01 de junho de 2016.

CAETANO, R. A Coca-Cola encolhe para crescer. IstoÉ Dinheiro, 12 fev. 2016. Disponível em: <http://www.istoedinheiro.com.br/noticias/negocios/20160212/coca-cola-encolhepara-crescer/342585>. Acesso em: 01 de junho de 2016.

A Cara do Rio. Coca-cola para as olimpíadas rio 2016 no porto maravilha. Rio de Janeiro, 12 jul. 2016. Disponível em: <http://acaradorio.com/coca-colapara-as-olimpiadas-rio-2016-no-porto-maravilha/>. Acesso em: 14 de outubro de 2016.

CARRO, R. Coca-Cola Brasil vê redução de consumos devido à crise econômica. Valor Econômico, 20 abr. 2016. Disponível em: <http://www.valor.com.br/empresas/4532491/coca-cola-brasil-ve-reducao-deconsumo-devido-crise-economica>. Acesso em: 09 de setembro de 2016

Coca-Cola Journey. Nós Respondemos. 11 mai. 2016. Disponível em: <http://www.cocacolabrasil.com.br/fale-conosco/nos-respondemos>. Acesso em: 09 de setembro de 2016 
Comitê Rio2016. Divulgadas as primeiras listas de condutores da tocha Olímpica: confira quem vai fazer história nos Jogos Rio 2016. Rio de Janeiro, 16 mar. 2016. Disponível em: <http://www.brasil2016.gov.br/pt$\mathrm{br} /$ noticias/divulgadas-as-primeiras-listas-de-condutores-da-tocha-confira-quemvai-fazer-historia-nos-jogos-rio-2016>. Acesso em: 14 de outubro de 2016.

DEARO, G. As $\mathbf{2 0}$ marcas mais indicadas pelas pessoas nas redes sociais. Exame.com, 29 jan. 2016. Disponível em: <http://exame.abril.com.br/marketing/noticias/as-20-marcas-mais-indicadaspelas-pessoas-nas-redes-sociais>. Acesso em: 18 de junho de 2016.

DEPEC Bradesco - Departamento de Pesquisas e Estudo Econômicos. Indústria de Bebidas. Jun. 2016. Disponível em: <http://www.economiaemdia.com.br/EconomiaEmDia/pdf/infset_industria_de_be bidas.pdf>. Acesso em: 09 de setembro de 2016.

Diário do Rio. Coca-Cola terá espaço de $1 \mathbf{~ k m}^{2}$ no Parque Olímpico durante a Rio 2016. Rio de Janeiro, 13 jul. 2016. Disponível em: $<$ http://diariodorio.com/coca-cola-tera-espaco-de-1-km\%C2\%B2-no-parqueolimpico-durante-rio-2016/>. Acesso em: 14 de outubro de 2016.

Entertainment and Media Outlook. Associação Brasileira de Empresas de Eventos. Grandes eventos de música aquecem o turismo brasileiro. Rio de Janeiro, 2015. Disponível em: <http://www.abeoc.org.br/2015/09/grandeseventos-de-musica-aquecem-o-turismo-brasileiro/>. Acesso em: 01 de junho de 2016.

O Estado de São Paulo. Lucro da Coca-Cola cai no $1^{\circ}$ tri e empresa cita fraqueza da economia do Brasil e Rússia. Estadão, 20 abr. 2016. Disponível em: <http://economia.estadao.com.br/noticias/negocios,coca-cola-tem-queda-nolucro-e-cita-fraqueza-em-brasil-e-russia--,10000027169>. Acesso em: 18 de junho de 2016.

Euromonitor International. Soft Drinks in Brazil. Disponível em: <http://www.euromonitor.com/soft-drinks-in-brazil/report>. Acesso em: $09 \mathrm{de}$ setembro de 2016

Fotógrafa amadora em Blog. Parque Olímpico Rio 2016 - Competições e muita diversão. Rio de Janeiro, 14 ago. 2016. Disponível em: $<$ http://inventandocomamamae.blogspot.com.br/2016/08/parque-olimpicorio2016-competicoes-e.html>. Acesso em: 14 de outubro de 2016.

IBGE (Instituto Brasileiro de Geografia e Estatística). Sinopse do Censo Demográfico para o Semiárido Brasileiro. Disponível em: $<\mathrm{http}: / /$ www.insa.gov.br/censosab/?option=com_content\&view=article\&id=101\&lt emid $=100$ >. Acesso em: 09 de setembro de 2016

Ibope Mídia. Gerações Y e Z: Juventude Digital. São Paulo, 2010. Disponível em: <http://www4.ibope.com.br/download/geracoes\%20_y_e_z_divulgacao.pdf >. Acesso em: 08 de setembro de 2016.

MEDEIROS, S. Marketing de experiências gera resultados além das vendas. 5Seleto Marketing Educacional Experts, 31 jan. 2016. Disponível em: $<\mathrm{http}: / / 5$ seleto.com.br/marketing-de-experiencia-gera-mais-que-vendas/>.

Acesso em: 22 de junho de 2016. 
Millward Brown para Coca-Cola Brasil. BGS: Brand Guidance System. Pesquisa relativa a consumo declarado. Brasil, janeiro-julho 2016.

Nielsen.a. 5 coisas que precisamos saber sobre o consumidor. Rio de Janeiro, 2016. Disponível em: <http://www.nielsen.com/br/pt/press-room/2016/5coisas-que-precisamos-saber-sobre-o-consumidor.html>. Acesso em: 18 de junho de 2016.

Nielsen.b para Coca-Cola Brasil. Retail Index Basis. Auditoria de mercado nos pontos de varejo. Brasil, 2015.

Nielsen.c para Paraíba Total. Analista aponta 5 mudanças sobre o consumo no Brasil. Abr. 2016.2 Disponível em: <http://www.paraibatotal.com.br/noticias/2016/04/01/00216-analista-aponta-5mudancas-sobre-o-consumo-no-brasil>. Acesso em: 09 de setembro de 2016

Portal Coca-Cola Brasil. Visão Geral, a Crônica da Coca-Cola. Rio de Janeiro, 2016. Disponível em: <http://www.cocacolabrasil.com.br/historia/a-cronica-dacoca-cola>. Acesso em: 08 de setembro de 2016.

PwC (Pricewaterhouse Coopers) para RPC. O show não pode parar: mercado de entretenimento está otimista. Paraná, 2015. Disponível em: $<$ http://www.deolhonomercado.com.br/economia/o-show-nao-pode-pararmercado-de-entretenimento-esta-otimista/>. Acesso em: 18 de junho de 2016.

RODERICK, L. Why Coca-Cola needs to focus on love not on logic as it evolves its one brand strategy. Marketing Week, 22 abr. 2016. Disponível em: $<$ https://www.marketingweek.com/2016/04/22/why-coca-cola-needs-to-focus-onlove-not-logic-as-it-evolves-its-one-brand-strategy/>. Acesso em: 20 de junho de 2016.

ROGATTO, G para Associação Brasileira de Empresas de Eventos. Brasil ocupa segundo lugar no mercado de eventos musicais da América Latina. 19 set. 2014. Disponível em: < http://www.abeoc.org.br/2014/09/brasil-ocupasegundo-lugar-no-mercado-de-eventos-musicais-da-america-latina/>. Acesso em: 01 de junho de 2016

SOUSA, D. Produção de refrigerante deve ter nova queda em 2016. O Estado de São Paulo, 08 abr. 2016. Disponível em: $<$ http://economia.estadao.com.br/noticias/geral,producao-de-refrigerante-deveter-nova-queda-em-2016,10000025622>. Acesso em: 01 de junho de 2016.

TITTOTO, G. Economia desacelera e consumidor brasileiro muda seu comportamento de consumo. Nielsen, 04 mai. 2015. Disponível em: <http://www.nielsen.com/br/pt/press-room/2015/Economia-desacelera-econsumidor-brasileiro-muda-seu-comportamento-de-consumo.html>. Acesso em: 09 de setembro de 2016

Top of Mind 2015 de Folha de São Paulo. Campeãs nos 25 anos comemoram marca histórica e nova vitória. São Paulo, 2015. Disponível em: <http://www1.folha.uol.com.br/topofmind/2015/10/1699093-campeas-nos-25anos-comemoram-marca-historica-e-nova-vitoria.shtml>. Acesso em: 18 de junho de 2016. 
WHIPP, L. Vendas da Coca crescem mais para bebida não gasosa do que refrigerante. Folha de São Paulo, 21 abr. 2016. Disponível em: <http://www1.folha.uol.com.br/mercado/2016/04/1763420-vendas-da-cocacrescem-mais-para-bebida-nao-gasosa-do-que-refrigerante.shtml>. Acesso em: 01 de junho de 2016.

\section{Vídeos:}

Coca-Cola Taste Games. Winnin.com. Duração: 4min08s. Disponível em: $<$ https://winnin.com/cocacolatastegames/>. Acesso em: 09 de setembro de 2016.

"I'd like to buy the world a Coke". Youtube.com. Duração: 1min. Disponível em: <https://www.youtube.com/watch?v=1VM2eLhvsSM>. Acesso em: 14 de outubro de 2016.

Parada Coca-Cola. Youtube.com. Duração: 5min04s. Disponível em: $<$ https://www.youtube.com/watch?v=xDefPUhe6nl>. Acesso em: 09 de setembro de 2016. 


\section{Anexo: Roteiro das Entrevistas}

1. Nome

2. Formação (breve histórico, tempo de empresa)

3. Perfil do cargo no projeto (atribuições, relação com o consumidor)

4. Histórico do projeto

5. Quais são as dificuldades de realizar uma experiência para o público?

6. Para a Coca-Cola, qual é o benefício de incluir uma experiência em um projeto?

7. Quando o briefing é montado, quais são os retornos esperados de uma brand experience?

8. Quando podemos afirmar que a experiência foi um sucesso?

9. E se uma experiência não for financeiramente viável, qual é o direcional da companhia?

10. Deste ponto de vista financeiro, como você enxerga uma experiência de marca?

11. E como você acha que uma experiência é vista pelos "decisores" de projetos na companhia, ainda financeiramente?

12. Quais barreiras você encontrou dentro da organização para realizar a experiência?

13. Você acredita que experiências são valorizadas pelo consumidor de hoje?

14. De 0 a 10, qual é, na sua opinião, o nível de envolvimento que uma experiência causa entre o consumidor e a marca? 